\title{
Mycobacterium canetti
}

National Cancer Institute

\section{Source}

National Cancer Institute. Mycobacterium canetti. NCI Thesaurus. Code C85547.

A species of Mycobacterium that is a member of the Mycobacterium tuberculosis

complex. It is characterized by smooth, shiny colonies, a shorter generation time, and a unique phenolic glycolipid and lipo-oligosaccharide. 